\title{
Design of RPFC for Power Quality Improvement in Railway Power System using Fuzzy logic Controller
}

\author{
K. Sathish Kumar \\ P. G Student EEE, \\ JNTUK-UCEV \\ Vizianagaram, Andhra Pradesh, India.
}

\author{
Dr. G. Saraswathi \\ M.E, Ph.D, M. B. A Professor EEE, \\ JNTUK-UCEV \\ Visakhapatnam, Andhra Pradesh, India.
}

\begin{abstract}
This paper is to create Power Quality in electric Railway systems with the assistance of Fuzzy Logic controller. Concentrating on the cargo prepare prevailing electrical railroad power system (ERPS) blended with air conditioning dc and air conditioning dc-air conditioning trains (its power factor $[0.70,0.84]$ ), this paper proposes a power factor situated railroad power flow controller (RPFC) for the power quality improvement of ERPS. In this paper the thorough relationship of the primary power factor, converter limit, and the two phase load currents are introduced. By this technique we can likewise control the power flow trade between the grid and the load, with the goal that instantaneous active and reactive power is maintain constant. Moreover, as the main commitment of this paper, the ideal remunerating procedure suited the irregular varied two phase loads is broke down and planned based on a genuine footing substation, for the reasons for fulfilling the power quality standard, improving RPFC's control adaptability, and diminishing converter's ability. Here we are utilizing the fuzzy controller contrasted with different controllers i.e. The fuzzy controller is the most reasonable for the human basic leadership component, giving the operation of an electronic system with choices of specialists. What's more, utilizing the fuzzy controller for a nonlinear system takes into account a decrease of indeterminate impacts in the system control and enhances the effectiveness. By utilizing simulation results we can examine the improvement of the power quality in electric railroad systems utilizing fuzzy logic controller.
\end{abstract}

Index Terms-Power factor; negative sequence; power quality; power flow controller; electrical railway power system; converter, Fuzzy logic controller

\begin{tabular}{ll} 
PF & \multicolumn{1}{c}{ NOMENCLATURE: } \\
PQ & Power factor \\
Power quality \\
Negative sequence current \\
NSV & Negative sequence voltage \\
DC & Direct Current \\
AC & Alternating Current \\
RPFC & Railway Power flow controller \\
ERPS & Electrical railway power systems \\
SVC & Static var compensator \\
STATCOM & Static synchronous compensator \\
OCS & Optimal compensating strategy \\
FCM & Fully compensation model \\
PLL & Phase Locked Loop \\
PWM & Pulse Width Modulation \\
PS & Proportional Resonant Regulator \\
FLC & Fuzzy logic controller
\end{tabular}

\section{INTRODUCTION}

Power quality has become an increasing concern in railway systems. Poor power quality affects the performance, reliability of the railway system as well as having an effect on equipment attached to the local distribution network. The analysis of power quality on a rail system is essential, to enable the analysis of train performance and to assess the effects of a rail system on the adjacent distribution network. Railway systems are electrically complex. The loads, trains, are constantly moving and their electrical behaviour is constantly changing. Modelling is an ideal tool to analyse the power quality of such a complex system. An ideal model would be accurate yet computationally efficient.

As the popular PQ improvement rig, static var compensator (SVC) [9], [10], static synchronous compensator (STATCOM) [11]-[15], active filter [16][21], transformer integrated power conditioner [22]-[24], railway power flow controller (RPFC) [5], [25]-[30], and the well-designed train-mounted front end rectifier [31][33] are commonly used in ERPS. Considering the comprehensive performance, RPFC is concerned greatly by related departments due to its compatibility - it can, unlike the above rigs, integrate in the secondary side of almost all kinds of traction transformer. By rebalancing the two phase active power, and compensating the reactive power or harmonics in each phase independently, RPFC can deal with almost all the main PQ problems of ERPS. Additionally, the feeder voltage's stability and the capacity utilization ratio of the main transformer can also be enhanced significantly [26], [30], which are attractive for improving ERPS's transport capacity and cost-efficiency.

Power Quality has to be considered from two perspectives, the railway system and the local distribution network to which it is attached. Poor power quality on the railway system affects performance limits capacity and may introduce a need for additional maintenance. Distribution network operators stipulate power quality standards. Railway systems are required to meet these standards. Power quality is divided into categories [1]. Railway systems typically suffer from poor voltage regulation and harmonic distortion. Voltage regulation affects the 
performance of traction units and imposes a capacity limit on the system. Harmonic distortion can cause damage to traction units, particularly motors [2]. Rail systems can cause harmonic distortion and voltage unbalance on the local distribution network. The harmonic distortion is caused by the non linear currents drawn by the railway system and in DC systems by rectifying substations. Voltage unbalance is present in AC systems, where the rail system draws large currents from a single phase of the supply.

To additionally enhance RPFC's ability usage capacity and control adaptability in both outlining and working stages in cargo prepare overwhelming ERPS, in this paper, we will center around the arrangement of the accompanying perspectives:

1) Establishing the connection between the primary $P F$ with RPFC's remunerating limit; the converter's ability can be adaptably composed by modifying the primary PF.

2) In the commence of limiting RPFC's ability for a given $\mathrm{PF}$, considering an ideal control system to diminishing NSC and NSV in a satisfactory level.

3) The proposed control procedure ought not exclusively be connected in the basic single phase ERPS, yet in addition in the vital regular utilized two phase system (see Fig.1).

This paper is sorted out as takes after, the mathematical model of the RPFC coordinated two phase ERPS is displayed in Section II. In the introduce of relief NSC, as the main commitment of this paper, Section III gives the PF situated ideal pay system for RPFC. Simulation are given in Section IV and V. Segment VI is the conclusion.

\subsection{Mathematical model of RPFC}

The frame-ABC by the $\mathrm{V} / \mathrm{v}$ transformer's primary three phase voltage $\mathrm{VA}, \mathrm{VB}$, and $\mathrm{VC}$

$$
\mathrm{V}_{\mathrm{A}}=V_{\mathrm{p}} \angle 0^{\circ}, \mathrm{V}_{\mathrm{B}}=V_{\mathrm{p}} \angle-120^{\circ}, \mathrm{V}_{\mathrm{c}}=V_{\mathrm{p}} \angle-240^{\circ}
$$

where $\mathrm{Vp}$ is the root mean square (RMS) value of $\mathrm{VA}, \mathrm{VB}$, and VC.

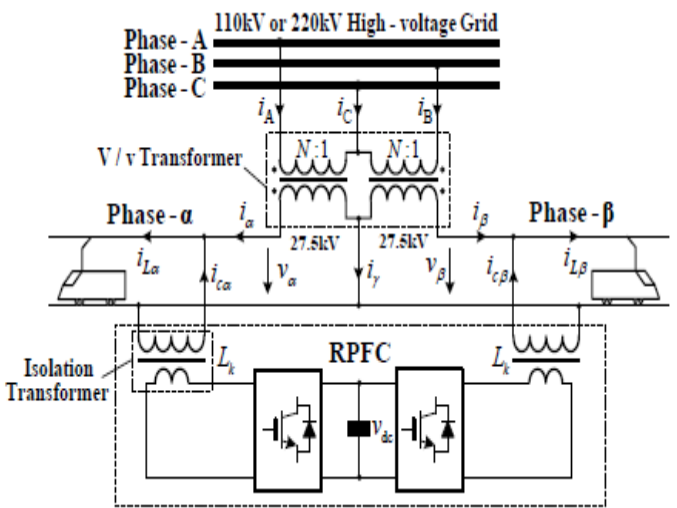

Fig. 1. The typical RPFC integrated two phase ERPS(V/v transformer is adopted as the main transformer).;

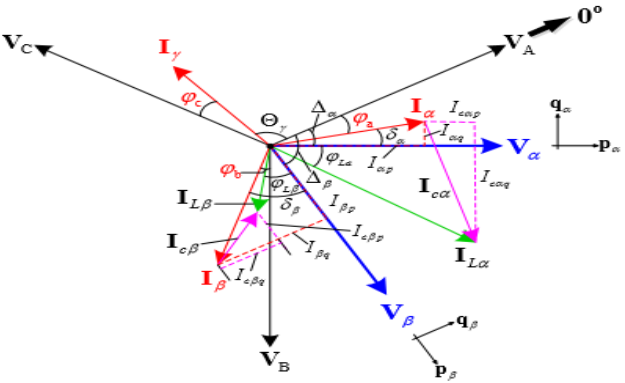

Fig 2: The phasor diagram of the V/v transformer based ERPC with RPFC.

From Fig. 2, we define the PF in phase-A, B, and C, i.e., PFA PFC as:

$P F_{A}=\cos \emptyset_{\mathrm{a}} \quad P F_{B}=\cos \emptyset_{\mathrm{b}} \quad P F_{C}=\cos \emptyset_{\mathrm{c}}$

Where, $\varphi \mathrm{k}>0$ means that the present slacks the voltage, generally, the present leads the voltage $(\mathrm{k}=\mathrm{a}, \mathrm{b}, \mathrm{c})$. It can be seen from Figs. 1 and 2 that, the output currents I $\alpha$ and I $\beta$ of the $V / v$ transformer in outline $p \alpha q \alpha$ and outline $p \beta q \beta$ (see Fig.2) can be

$\mathrm{I}_{\alpha}=\mathrm{I}_{\mathrm{L} \alpha}-\mathrm{I}_{\mathrm{C} \alpha}=\left(\mathrm{I}_{\mathrm{L} \alpha \mathrm{p}}-\mathrm{I}_{\mathrm{C} \alpha \mathrm{p}}\right)+\mathrm{j}\left(\mathrm{I}_{\mathrm{L} \alpha \mathrm{q}}-\mathrm{I}_{\mathrm{C} \alpha \mathrm{q}}\right)$

$I_{\beta}=I_{L \beta}-I_{C \beta}=\left(I_{L \beta p}-I_{C \beta p}\right)+j\left(I_{L \beta q}-I_{C \beta q}\right)$

Where, subscript "p" and "q" speaks to the active and reactive component of the relating variable in outline $p \alpha q \alpha$ or outline $\mathrm{p} \beta \mathrm{q} \beta$, separately. Furthermore, Fig. 2 additionally demonstrates that the relationship of the $p, q$ components of $\mathrm{I} \alpha$ and $\mathrm{I} \beta$ in outline $\mathrm{p} \alpha \mathrm{q} \alpha$ and $\mathrm{p} \beta \mathrm{q} \beta$ fulfill: $\mathrm{I}_{\alpha \mathrm{q}}=\mathrm{I}_{\alpha \mathrm{p}} \tan \delta_{\alpha}=\left(\mathrm{I}_{\mathrm{L} \alpha \mathrm{p}}-\mathrm{I}_{\mathrm{C} \alpha \mathrm{p}}\right) \tan \delta_{\alpha}$

$\mathrm{I}_{\beta \mathrm{q}}=\mathrm{I}_{\beta \mathrm{p}} \tan \delta_{\beta}=\left(\mathrm{I}_{\mathrm{L} \beta \mathrm{p}}-\mathrm{I}_{\mathrm{C} \beta \mathrm{p}}\right) \tan \delta_{\beta}$

$\delta_{\alpha}=\Delta_{\alpha}-\emptyset_{\mathrm{a}}$

$\delta_{\beta}=\Delta_{\beta}-\emptyset_{\mathrm{b}}-120$

Note: for $\mathrm{V} / \mathrm{v}$ transformer, $\Delta \alpha=30^{\circ}, \Delta \beta=90^{\circ}$. Disregarding the converter's losses, and accepting $\mathrm{V} \alpha=\mathrm{V} \beta$, the active power adjust of the consecutive converter can lead the consequence of:

$\Delta_{\alpha}=30 \quad \Delta_{\beta}=90$

$\mathrm{V}_{\alpha}=\mathrm{V}_{\beta}$

$\mathrm{I}_{\mathrm{C} \alpha \mathrm{p}}=-\mathrm{I}_{\mathrm{C} \beta \mathrm{p}}$

Then again, Fig. 2 shows that I $\gamma^{\prime}$ s phase point $\Theta \gamma$ in outline ABC fulfil

$\theta_{\gamma}=120^{\circ}-\emptyset_{c}$ or $\tan \theta_{\gamma}=\tan \left(120^{\circ}-\emptyset_{c}\right)$.

Based on kirchhoff's law , $\mathrm{I}_{\alpha}, \mathrm{I}_{\beta}, \mathrm{I}_{\gamma}$ in frame $\mathrm{ABC} \mathrm{I}_{\alpha}^{\mathrm{ABC}}$, $\mathrm{I}_{\beta}^{\mathrm{ABC}}, \mathrm{I}_{\gamma}^{\mathrm{ABC}}$ satisfy

$-\mathrm{I}_{\gamma}=-\mathrm{I}_{\gamma}^{\mathrm{ABC}}=\mathrm{I}_{\alpha}^{\mathrm{ABC}}+\mathrm{I}_{\beta}^{\mathrm{ABC}}$,

$\mathrm{I}_{\alpha}^{\mathrm{ABC}}=\mathrm{I}_{\alpha}$ 
Substituting (3), (4), and (8) into (7), the genuine and nonexistent piece of - I $\gamma$, Term-I and Term-II, can be computed as

$\mathrm{I}_{\alpha \mathrm{p}} \cos \Delta_{\alpha}+\mathrm{I}_{\alpha \mathrm{q}} \sin \Delta_{\alpha}+\mathrm{I}_{\beta \mathrm{p}} \cos \Delta_{\beta}+\mathrm{I}_{\beta \mathrm{q}} \sin \Delta_{\beta}$

$-\mathrm{I}_{\alpha \mathrm{p}} \sin \Delta_{\alpha}+\mathrm{I}_{\alpha \mathrm{q}} \cos \Delta_{\alpha}-\mathrm{I}_{\beta \mathrm{p}} \sin \Delta_{\beta}+\mathrm{I}_{\beta \mathrm{q}} \cos \Delta_{\beta}$

Substituting (9) into (6), and considering the expressions of $\mathrm{I} \alpha \mathrm{p}, \mathrm{I} \alpha \mathrm{q}, \mathrm{I} \beta \mathrm{p}$, and I $\beta \mathrm{q}$ in (3)-(5), the relationship of Ic $\alpha \mathrm{p}$ with the two phase load active currents IL $\alpha$ p and IL $\beta p$ can be calculated as

$\mathrm{I}_{\mathrm{C} \alpha \mathrm{p}}=\frac{x_{1}}{x_{1}+x_{2}} I_{L \alpha p}-\frac{x_{2}}{x_{1}+x_{2}} I_{L \beta p}$

$x_{1}=\sin \theta_{\alpha}-\cos \theta \alpha \tan \delta_{\alpha}$ $\theta_{\alpha}=\Delta_{\alpha}$

$\emptyset_{\mathrm{c}}+120^{\circ}$

$\theta_{\beta}=\Delta_{\beta}-$

$x_{2}=\cos \theta_{\beta} \tan \delta_{\beta}-\sin \theta_{\beta}$

$\emptyset_{\mathrm{c}}+120^{\circ}$

Re-substituting (10) into (3)- (5), the remunerating currents of RPFC can be acquired as

$\mathrm{I}_{\mathrm{C} \alpha \mathrm{p}}=\mu_{\alpha} I_{L \alpha p}-\mu_{\beta} I_{L \beta p}$

$\mathrm{I}_{\mathrm{C} \beta \mathrm{p}}=-\mu_{\alpha} I_{L \alpha p}+\mu_{\beta} I_{L \beta p}$

$\mathrm{I}_{\mathrm{C} \alpha \mathrm{q}}=-\left[\tan \emptyset_{\mathrm{L} \alpha}+\left(1-\mu_{\alpha}\right) \tan \delta_{\alpha}\right] I_{L \alpha p}-\mu_{\beta} \tan \delta_{\alpha} I_{L \beta p}$ (11)

$\mathrm{I}_{\mathrm{C} \beta \mathrm{q}}=\mu_{\alpha} \tan \delta_{\beta} I_{L \alpha p}-\left[\tan \emptyset_{\mathrm{L} \beta}+\left(1-\mu_{\beta}\right) \tan \delta_{\beta}\right] I_{L \beta p}$

Increasing the feeder voltage $\mathrm{V} \alpha$ or $\mathrm{V} \beta$ in the two sides of (11), RPFC's remunerating power in phase $\alpha$ and $\beta$, i.e., Pc $\alpha$, Qc $\alpha$ and $\operatorname{Pc} \beta$, Qc $\beta$, can be ascertained as

$\mathrm{P}_{\mathrm{C} \alpha}=\mu_{\alpha} P_{L \alpha}-\mu_{\beta} P_{L \beta}$

$\mathrm{P}_{\mathrm{C} \beta}=-\mu_{\alpha} P_{L \alpha}+\mu_{\beta} P_{L \beta}$

$\mathrm{Q}_{\mathrm{C} \alpha}=-\left[\tan \emptyset_{\mathrm{L} \alpha}+\left(1-\mu_{\alpha}\right) \tan \delta_{\alpha}\right] P_{L \alpha}-\mu_{\beta} \tan \delta_{\alpha} P_{L \beta}$ (12)

$\mathrm{Q}_{\mathrm{C} \beta}=\mu_{\alpha} \tan \delta_{\beta} P_{L \alpha}-\left[\tan \emptyset_{\mathrm{L} \beta}+\left(1-\mu_{\beta}\right) \tan \delta_{\beta}\right] P_{L \beta}$

\begin{tabular}{|l|l|l|l|}
\hline Compensating model & \multicolumn{1}{|c|}{$\emptyset_{a}$} & $\emptyset_{b}$ & $\emptyset_{c}$ \\
\hline Model-1 & 0 & 0 & 0 \\
\hline Model-2 & $>0$ & $<0$ & $>0$ \\
\hline Model-3 & $>0$ & $<0$ & $<0$ \\
\hline Model-4 & $>0$ & $>0$ & $>0$ \\
\hline Model-5 & $>0$ & $>0$ & $<0$ \\
\hline
\end{tabular}

Where, PL $\alpha$ and PL $\beta$ are the load's active power in phase $\alpha$ and $\beta$. It can be seen from (12), in light of the fact that $\Delta \alpha$, $\Delta \beta$ can be pre-acquired for a specific sort of a transformer (e.g., the V/v transformer and other sort of the adjust transformers [35], [36]), $\mu \alpha$ and $\mu \beta$ are just dictated by PFA PFC or $\varphi \mathrm{a} \sim \varphi c$ [see (10) and (2)]. Henceforth, the active and reactive power of the RPFC can be adaptably balanced by controlling the primary three phase power factors, if the PFs of the two phase loads are pre-ascertained [see $\varphi \mathrm{L} \alpha$ and $\varphi \mathrm{L} \beta$ in (12)], which will be talked about later on.

\section{COMPENSATING STRATEGY DESIGN}

A.The Possible Compensating Scheme:

For the consideration of planning accommodation and the necessity of $P F \geq 0.9$, we let

$\left|\emptyset_{a}\right|=\left|\emptyset_{b}\right|=\left|\emptyset_{c}\right|$

$\mathrm{PF}^{*}=\cos \emptyset_{\mathrm{k}} \in[0.9,1], \mathrm{k}=\mathrm{a}, \mathrm{b}, \mathrm{c}$

Where $\mathrm{PF}^{*}$ is the primary reference power factor. It can be observed from Fig. 2 that $\mathrm{I} \alpha, \mathrm{I} \beta$, and $\mathrm{I} \gamma$ (or IA, IB, and IC) may leads or slacks VA, VB, and VC, individually, which means eight (i.e., $8=23$ ) conceivable combination models with positive or negative esteem are existed in $\varphi \mathrm{a}, \varphi \mathrm{b}$, and $\varphi c$. In addition, Fig. 2 additionally demonstrates the reactive power of converter- $\alpha$ is bigger than the one created by converter- $\beta$ (i.e., Ic $\alpha \mathrm{q}>\mathrm{Ic} \beta \mathrm{q}$ ), to lessen the VAlimit of converter- $\alpha$, I $\alpha$ must be confined slacking than VA (i.e., $\varphi \mathrm{a}>0$ ), so the over eight conceivable combination models of $\varphi \mathrm{\sim} \sim \varphi \mathrm{c}$ will decline into four profitable hopefuls, which are recorded in Table I (i.e., Model-2 to - 5).

\section{B. Compensating Capacity Analysis:}

The VA-capacity SRPFC of the RPFC is:

$\mathrm{S}_{\mathrm{RPFC}}=\sqrt{P_{c \alpha}^{2}+Q_{c \alpha}^{2}}+\sqrt{P_{c \beta}^{2}+Q_{c \beta}^{2}}$

Substituting (12) into (14), the RPFC's VAlimit in the five repaying model recorded in Table I are appeared in Fig. 3 [PL $\alpha$ and PL $\beta$ are the two phase loads' active power, $\mathrm{PF}^{*}=0.95$, and the two phase loads' $\mathrm{PF}=0.8$ (from a substation'sdata)]. It can be seen from Fig. 3(a) that, the VA-limit of RPFC has a place with five unique surfaces in Model-1 5 individually. The maximum SRPFC happens in the single phase loaded condition, in which Model-1, 2, and 4 compare to PL $\alpha \neq 0, P L \alpha \beta=0$, while the contrary circumstance has a place with Model-3 and 5. (a) (b)

$\left.\mathrm{OCS}\right|_{P F *}=0.95 \quad$ MODEL-5, $0 \mathrm{MW} \leq P_{L \beta}<0.55 P_{L \alpha}$

MODEL-4, $\quad 0.55 P_{L \alpha} \leq P_{L \beta} \leq 1.67 P_{L \alpha}$

MODEL-2, $1.67 P_{L \alpha}<P_{L \beta} \leq 8 \mathrm{MW}$

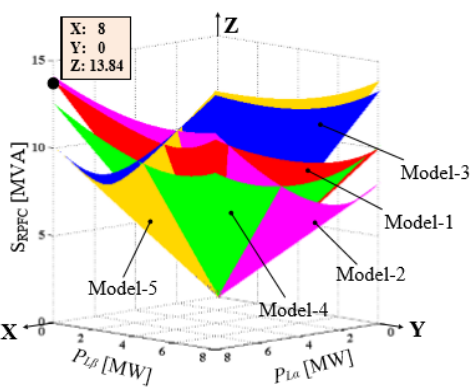

Fig 4.2 : The surfaces of SRPFC with the two phase loads' active power. 


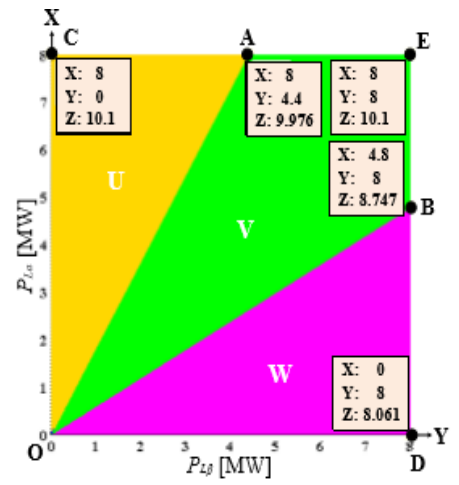

Fig 4.3: The xoy-projection of the surfaces

Fig. 3. The relationship of SRPFC with the two phaseloads' active power in the five valuable compensatingmodels. (a) The surfaces of SRPFC with the two phase loads' active power. (b) The xoy-projection ofthe surfaces in Fig. 3(a).

\section{C.The NSC Mitigation Ability Analysis}

But of remunerating reactive power, alleviation of the NSC is another motivation behind RPFC. In other words, a satisfactory repaying technique ought to limit SRPFC, as well as has the obligation to diminish NSC inside a satisfactory level.

\section{The NSC Mitigation Ability Analysis}

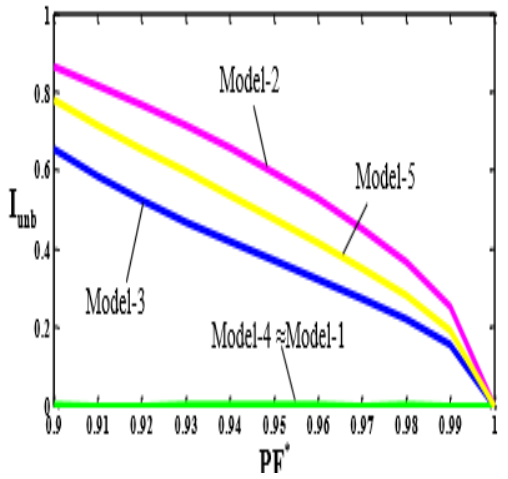

Fig 4.4: The curves of Iunb vs $\mathrm{PF}^{*}$ of Model-1 5

Combing (7)-(8), the primary positive and negative sequence currents, I+ and I-, can be deduced by

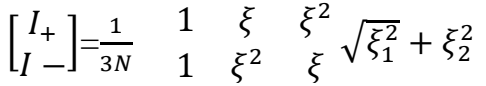

$$
\begin{aligned}
& =\frac{\mu_{\beta}\left(I_{L \alpha p}+I_{L \beta p}\right)\left(1+j \tan \delta_{\alpha}\right)}{\sqrt{3} N}\left[\begin{array}{l}
\angle-\left(\Delta_{\alpha}-30^{\circ}\right) \\
\angle-\left(\Delta_{\alpha}+30^{\circ}\right)
\end{array}\right] \\
& +\frac{\mu_{\alpha}\left(I_{L \alpha p}+I_{L \beta p}\right)\left(1+j \tan \delta_{\beta}\right)}{\sqrt{3} N}\left[\begin{array}{l}
\angle-\left(\Delta_{\beta}-90^{\circ}\right) \\
\angle-\left(\Delta_{\beta}+90^{\circ}\right)
\end{array}\right]
\end{aligned}
$$

where $\xi=\angle 120^{\circ}, N=V s N / V f N$ is the turn's ratio of the main transformer ( $V s N$ and $V f N$ are the grid and feeder normal line voltage respectively; as shown in Fig. 1).

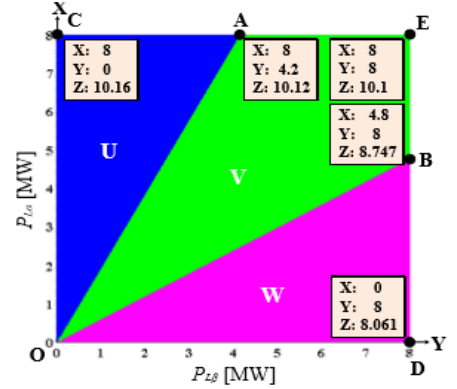

Fig 4.5: The optimal compensating strategy of considering the NSC suppressing ability.

$I_{\text {ubb }}=\sqrt{\frac{\mu_{\alpha}{ }^{2} \cos ^{2} \delta_{\alpha}+\mu_{\beta}{ }^{2} \cos ^{2} \delta_{\beta}+2 \mu_{\alpha} \mu_{\beta} \cos \delta_{\alpha} \cos \delta_{\beta} \cos \left(\varphi_{a}-\varphi_{\mathrm{b}}-180^{\circ}\right)}{\mu_{\alpha}{ }^{2} \cos ^{2} \delta_{\alpha}+\mu_{\beta}{ }^{2} \cos ^{2} \delta_{\beta}+2 \mu_{\alpha} \mu_{\beta} \cos \delta_{\alpha} \cos \delta_{\beta} \cos \left(\varphi_{\mathrm{a}}-\varphi_{\mathrm{b}}-60^{\circ}\right)}}$

From (13), (17), and Table I, the relationship of Iunb and PF* of Model-1 5 are shown in Fig. 4 and Fig. 3 (a), we can observe that,however the limit surfaces of Model-3 and 5 are close[Fig. 3 (a)], the NSC stifling capacity of Model3 issuperior to that of Model-5 (Fig. 4). It demonstratesthat, if Model-5 is substituted by Model-3, RPFC canshow signs of improvement NSC stifling capacitywith nearly has a similar VA limit of Model-5. In other words, the remunerating procedure joined of Model-2, 4, and 3 has higher exhaustive execution than the one consolidated by Model-2, 4, and 5. So the certified OCS ought to be adjusted from Fig. 3(b) into Fig. 5, and its determination is given in (18).

$\left.\mathrm{OCS}\right|_{P F *}=0.95 \quad$ MODEL-3, $0 \mathrm{MW} \leq P_{L \beta}<0.415 P_{L \alpha}$

MODEL-4, $\quad 0.55 P_{L \alpha} \leq P_{L \beta} \leq 1.67 P_{L \alpha}$

MODEL-2, $\quad 1.67 P_{L \alpha}<P_{L \beta} \leq 8 \mathrm{MW}$

Fig. 6 gives the slants of line $\mathrm{OA}$ and $\mathrm{OB}$, i.e., KOA and $\mathrm{KOB}$ in various $\mathrm{PF}^{*}$ (note: $\mathrm{OA}$ and $\mathrm{OB}$ are the limits of the three remuneration demonstrate appeared in Fig. 5; the loads' PF are as yet affirmed to be 0.8 , on the grounds that the power factor changes in a little rang around 0.8 in the deliberate substation). It can be observed from Fig. 6 that, KOA's change amplitude is 0.114, while, it fluctuates in generally expansive range for KOB. For execution of the proposed OCS, a satisfactory execution can likewise be acquired by settling KOAon 0.5 , and modifying KOB by PF* concurring the blue bend appeared in Fig. 6. It can be pre-implantedin the advanced controller's memory space in useful application.

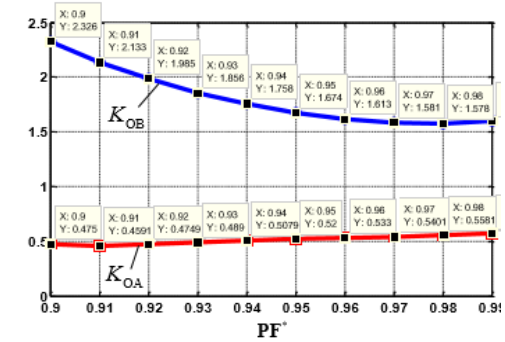

Fig 4.6: The curves of slope-AO and BO vs $\mathrm{PF}^{*}$. 


\section{Negative Sequence Standard Consideration}

From (16), the primary NSC I- can be calculated as:

$$
\begin{gathered}
I_{-}=\frac{1}{\sqrt{3 N}} \sqrt{\xi_{1}^{2}}+\xi_{2}^{2}\left(I_{L \alpha p}+I_{L \beta p}\right) \\
\xi_{1}=\mu_{\alpha}\left[\tan \delta_{\beta} \cos \Delta_{\beta}-\sin \Delta_{\beta}\right]+\mu_{\beta}\left[\cos \left(\Delta_{\alpha}+30\right)\right. \\
\left.+\tan \delta_{\alpha} \sin \left(\Delta_{\alpha}+30\right)\right] \\
\xi_{2}=\mu_{\beta}\left[\tan \delta_{\alpha} \cos \left(\Delta_{\alpha}+30\right)-\sin \left(\Delta_{\alpha}+30\right)\right]- \\
\mu_{\alpha}\left[\tan \delta_{\beta} \sin \Delta_{\beta}+\cos \Delta_{\beta}\right]
\end{gathered}
$$

The negative sequence capacity $\mathrm{S}$ - in the primary side is

$$
S_{-}=\sqrt{3} V_{S N} I_{-}=\mathrm{K}\left(P_{L \alpha}+P_{L \beta}\right)
$$

Considering the Chinese national standard of the negative sequence component is

$V_{u n b}=\frac{V_{-}}{V_{+}}=\frac{S_{-}}{S_{d}} \leq \varepsilon_{v}=2 \%$

Where $\mathrm{V}$ - and $\mathrm{V}+$ are the primary negative and positive voltages, $\mathrm{Sd}$ is the short out limit of the footing substation.

The negative sequence prerequisite of the proposed system can be figured by joining (20) and (21), i.e.,

$$
\mathrm{K}\left(P_{L \alpha}+P_{L \beta}\right) \leq S_{d} \times 2 \%
$$

Fig. 7 gives the two phase loads' distribution graph of a genuine $\mathrm{V} / \mathrm{v}$ transformer based footing substation (see Table II). The measurement results of Fig. 7 demonstrate that right around $95.2 \%$ of the loadpoints are situated in the rectangle zone of CEDO, where the likelihood of the points distributed in $\triangle \mathrm{ACO}$ and $\triangle \mathrm{ABO}$ (or $\triangle \mathrm{AB} 1 \mathrm{O}$, or $\triangle \mathrm{AB} 2 \mathrm{O}$ ) is around $85 \%$. Besides, we can likewise locate that, surpassing half of the load points are situated at stake OC and OD (take note of: a few points are covered on these two lines), which means the V/v transformer's ability usage ratio can be additionally improved in a vast potential. Based on the above measurement results, our consideration ought to be centered around the loads situated in CEDO and its limits.

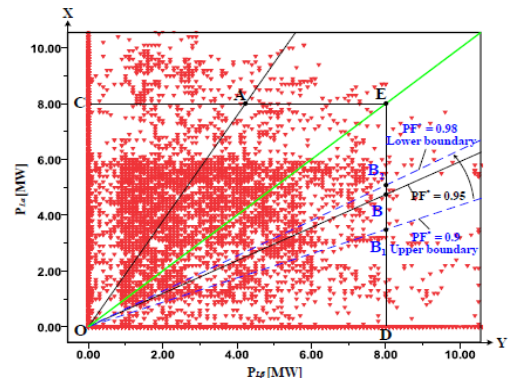

Fig. 7. The two phase load's distribution of a real V/v transformer based traction substation.

The surface of S - versus PL $\alpha$ and PL $\beta$ (inside rectangle region of CEDO appeared in Fig. 7) can be gotten based on (20) and the Sd given in TableII, which is appeared in Fig.
8. From the state of thesurfaces appeared in Fig. 8, it can be reasoned that the maximum $\mathrm{S}$ - of Model-3, 2, and 4 happens on the point $\mathrm{A}, \mathrm{B}$, and $\mathrm{E}$ for any given $\mathrm{PF}^{*}$, individually.

Table II

The Specification Of A Real V/V Transformer

\begin{tabular}{|l|l|}
\hline Grid line voltage & $110 \mathrm{KV}$ \\
\hline Transformer capacity & $\begin{array}{l}20 \mathrm{MVA} \\
\text { phase- } \alpha: 10 M V A \\
\text { phase- } \beta: 10 \mathrm{MVA}\end{array}$ \\
\hline $\begin{array}{l}\text { Sd of the traction } \\
\text { substation }\end{array}$ & $486 \mathrm{MVA}$ \\
\hline Short circuit impedance & phase- $\alpha$ and $\beta: 10 \%$ \\
\hline Turn's ratio & $110 \mathrm{kV}: 27.5 \mathrm{kV}$ \\
\hline
\end{tabular}

The surface of S - vs. PL $\alpha$ and PL $\beta$ (within rectangle area of CEDO shown in Fig. 7) can be obtained based on (20) and the Sd given in Table II, which is shown in Fig. 8. From the shape of the surfaces shown in Fig. 8, it can be concluded that the maximum S - of Model-3, 2, and 4 occurs on the point $\mathrm{A}, \mathrm{B}$, and $\mathrm{E}$ for any given $\mathrm{PF}^{*}$, respectively

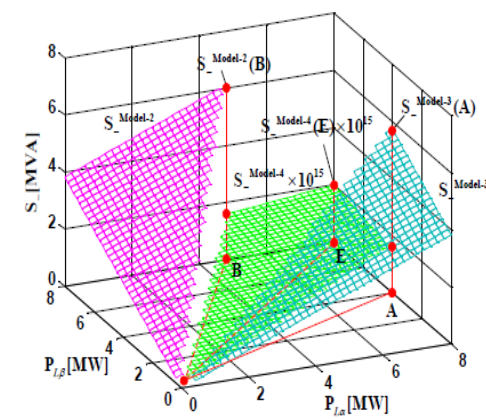

Fig. 8. The relationship of S- with PL $\alpha$ and PL $\beta$ (note: $\mathrm{PF}^{*}=0.95$ )

Fig. 9 gives the relationship of the $\mathrm{S}$-in $\mathrm{A}, \mathrm{B}$, and $\mathrm{E}$, i.e., the maximum $\mathrm{S}-, \mathrm{S}-\mathrm{max}$, with $\mathrm{PF}^{*}$ for this footing substation in Model-2 4. Clearly, the Sblocking capacity of Model-4 is greatly improved than that of Model-3 and 2, however the last's S-max diminishes when PF* turns out to be extensive. Fig. 9 additionally demonstrates that the maximum negative sequence powers controlled by OSC are not as much as the authorization esteem 9.72MVA (i.e., $486 \mathrm{MVA} \times 2 \%$ ), which means the Chinese national standard can be fulfilled when $\mathrm{PF}^{*}$ is set inside 0.9 to 0.99 . It ought to be commented here is that, if the authorization line of $\mathrm{S}$ crosses with other maximum Sline of Model-2 or 3 appeared in Fig. 9, the correct hand abscissa of that intersection point ought to be chosen as the important PF*, on the grounds that the left one will lead Vunb out of the utmost. 


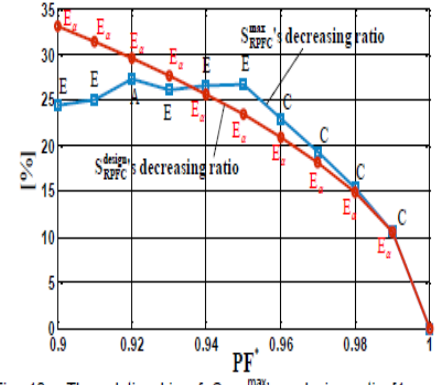

Fig. 9.The relationship of the primary maximum negative capacity with $\mathrm{PF}^{*}$ in Modle-2, 3 , and 4

The capacity utilization capability of RPFC should also be included in our concerning scope. From Fig. 10, the maximum SRPFC's (i.e., SRPFCmax) reducing ratio decreases heavily when $\mathrm{PF}^{*}>0.95$ [note: the maximum $S R P F C$ point in $P L \alpha-P L \beta$ panel (i.e., Fig. 7) is labeled in Fig. 10]. Besides, RPFC's designing capacity SRPFCdesign's decreasing ratio also shows relatively large value $(>23.43 \%)$ when $\mathrm{PF}^{*} \epsilon[0.9,0.95]$, it increases when $\mathrm{PF}^{*} \rightarrow 0.9$ [note: (1) SRPFCdesign $=2 \times \max \{$ Sconveter $-\alpha$, Sconveter- $\beta\}$, this is because IGBT is a voltage sensitive device and the dc-link voltages of converter- $\alpha$ and $\beta$ are the same; (2) $\mathrm{E} \alpha$ in Fig.10 means the maximum converter capacity belongs to converter- $\alpha$ located in point E]. Considering cost-efficiency, $\mathrm{PF}^{*}$ can be selected from 0.9 to 0.95 for this traction substation.

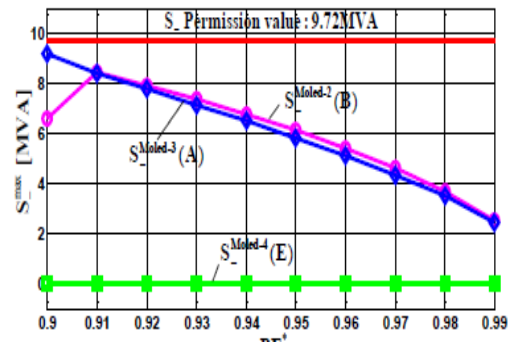

Fig. 10. The relationship of SRPFCmax's reducing ratio [1-maximum SRPFC/FCM based maximum SRPFC] and SRPFCdesign's reducing ratio [1-

SRPFCdesign /FCM based SRPFCdesign] with PF*

\section{E.Control Strategy Realization}

under the control of OCS.

The control system of the RPFC is plotted in Fig. 11. A few particulars ought to be made for it: The FFT strategy or the instantaneous reactive power theory [37] can be utilized for the estimation of the load's active and reactive power in the "PQ block", while the relative resounding controller (PS) is received as the present controller for its great following capacity in sing phase system. For the adjustment of vdc in the back-to - back system, rather than the figured Pc $\alpha$, the genuine Pc $\alpha$ is produced by the dc-link voltage PI controller in converter- $\alpha$. Furthermore, more consideration must be paid on the acknowledgment of the "repaying power figuring" block, and the accompanying four steps can help us to get the objective:

1) According the deliberate two phase loads (e.g., Fig. 7), Sd, and the exhibited slops of OA and OB appeared in Fig. 6, the PF*'s directing extent can be resolved for the motivations behind fulfilling the negative sequence's standard (e.g., Fig. 9) and having generally little limit (e.g., Fig. 10).

2) Based on the pre-set $\mathrm{PF}^{*}$ (e.g., $\mathrm{PF}^{*} \in[0.9,0.95]$ ), the inclines of $\mathrm{OA}$ and $\mathrm{OB}$ can be resolved from Fig. 6 .

The remunerating model of OCS can be controlled by the load point's area in the load distribution panel appeared in Fig. 5 or 7, which can be reasoned by distinguishing

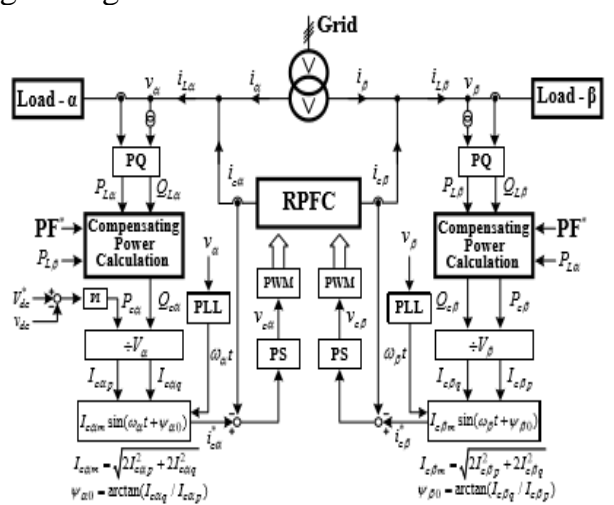

4) If the repaying model is gotten from step 3, $\varphi \mathrm{a}, \varphi \mathrm{b}$, and $\varphi c$ can be figured from Table I and (13), so as $\mu \alpha$ and $\mu \beta$ [see (10)]. Consequently, the repaying active and reactive power of RPFC can be at long last gotten from (12), [note: in (12),

$\varphi \mathrm{L} \alpha=\arctan (\mathrm{QL} \alpha / \mathrm{PL} \alpha), \varphi \mathrm{L} \beta=\arctan (\mathrm{QL} \beta / \operatorname{PL} \beta)]$.

\section{FUZZY LOGIC CONTROLLER:}

In FLC, basic control action is determined by a set of linguistic rules. These rules are determined by the system. Since numerical variables are converted into linguistic variables, mathematical modeling of the system is not required in $\mathrm{FC}$.

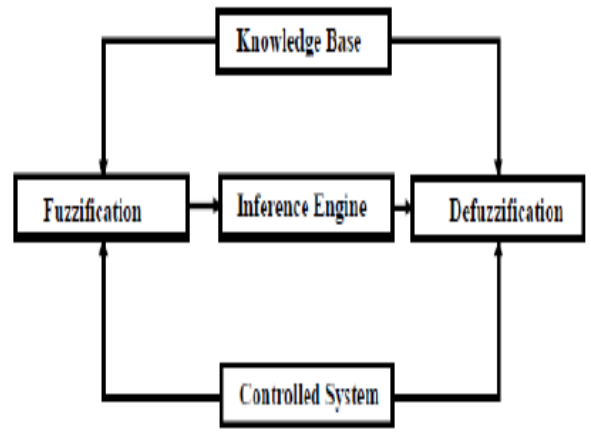

The FLC comprises of three parts: fuzzification, interference engine and defuzzification. The FC is characterized as i. seven fuzzy sets for each input and output. ii. Triangular membership functions for simplicity. iii. Fuzzification using continuous universe of discourse. iv. Implication using Mamdani's, 'min' operator. v. Defuzzification using the height method. 


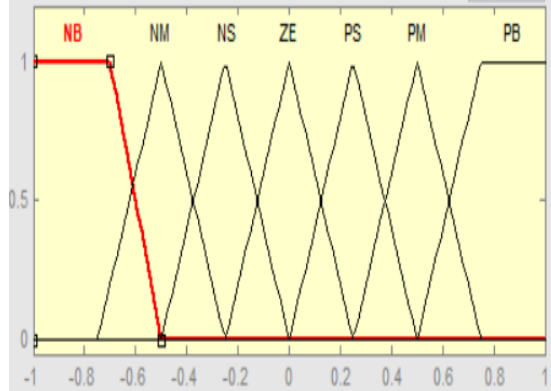

Fuzzification: Membership function values are assigned to the linguistic variables, using seven fuzzy subsets: NB (Negative Big), NM (Negative Medium), NS (Negative Small), ZE (Zero), PS (Positive Small), PM (Positive Medium), and PB (Positive Big). The Partition of fuzzy subsets and the shape of membership $C E(k) E(k)$ function adapt the shape up to appropriate system. The value of input error and change in error are normalized by an input scaling factor

Table 4.3: Rule Base Table of 7*7 Matrix[44]

\begin{tabular}{|c|c|c|c|c|c|c|c|}
\hline & NB & NM & NS & $\mathbf{Z E}$ & PS & PM & PB \\
\hline NB & PB & PB & PB & PM & PM & PS & $\mathrm{ZE}$ \\
\hline NM & PB & PB & PM & PM & PS & $\mathrm{ZE}$ & $\mathrm{ZE}$ \\
\hline $\mathbf{N S}$ & PB & PM & PS & PS & $\mathrm{ZE}$ & $\mathrm{NM}$ & NB \\
\hline $\mathbf{Z E}$ & PB & PM & PS & $\mathrm{ZE}$ & $\mathrm{NS}$ & $\mathrm{NM}$ & $\mathrm{NB}$ \\
\hline PS & PM & PS & $\mathrm{ZE}$ & NS & NM & NB & NB \\
\hline $\mathbf{P M}$ & PS & $\mathrm{ZE}$ & $\mathrm{NS}$ & $\mathrm{NM}$ & $\mathrm{NM}$ & $\mathrm{NB}$ & NB \\
\hline PB & $\mathrm{ZE}$ & NS & NM & $\mathrm{NM}$ & $\mathrm{NB}$ & NB & NB \\
\hline
\end{tabular}

Defuzzification: As a plant usually requires a non fuzzy value of control, a defuzzification stage is needed. To compute the output of the FLC,height method is used and the FLC output modifies the control output. Further, the output of FLC controls the switch in the inverter. In UPQC, the active power, reactive power, terminal voltage of the line and capacitor voltage are required to be maintained. In order to control these parameters, they are sensed and compared with the reference values. To achieve this, the membership functions of FC are: error, change in error and output.

The set of FC rules are derived from $\mathrm{u}=-\left[\alpha \mathrm{E}+(1-\alpha)^{*} \mathrm{C}\right](24)$

Where $\alpha$ is self-adjustable factor which can regulate the whole operation. $\mathrm{E}$ is the error of the system, $\mathrm{C}$ is the change in error and $u$ is the control variable. A large value of error $E$ indicates that given system is not in the balanced state. If the system is unbalanced, the controller should enlarge its control variables to balance the system as early as possible. One the other hand, small value of the error $\mathrm{E}$ indicates that the system is near to balanced state.

\section{SIMULATION RESULTS \\ THE PARAMETERS OF THE ISOLATION \\ TRANSFORMER AND RPFC}

\begin{tabular}{|l|c|}
\hline The VA-capacity of IT & 5MVA \\
\hline Short circuit impendence of IT & $21 \%$ \\
\hline IT's turn's ratio & $27.5 \mathrm{KV}: 27.5 \mathrm{KV}$ \\
\hline The dc-link voltage of RPFC & $51.15 \mathrm{KV}$ \\
\hline
\end{tabular}

TABLE IV

ACTION SEQUENCE OF THE CASE SHOWN IN FIG. 12

\begin{tabular}{|l|l|l|l|}
\hline Time & PF* & $\begin{array}{l}\text { Compensation } \\
\text { model }\end{array}$ & $\begin{array}{l}\text { Load } \\
\text { condition }\end{array}$ \\
\hline $0.0-0.25$ & No RPFC & - & \\
\hline $0.2-0.45$ & 0.90 & Model-3 & $\begin{array}{l}P_{L=}=8 \mathrm{MW}, \\
Q_{L=}=6 \mathrm{Mvar} \\
P_{L G}=0 \mathrm{MW}, \\
Q_{L \theta}=0 \mathrm{Mvar}\end{array}$ \\
\hline $0.4-0.6 \mathrm{~s}$ & 0.95 & Model-3 & \\
\hline $0.6-0.8 \mathrm{~s}$ & 0.97 & Model-3 & \\
\hline $0.8-15$ & 1.00 & FCM & \\
\hline
\end{tabular}

TABLE V

ACTION SEQUENCE OF THE CASE SHOWN IN FIG. 13

\begin{tabular}{|c|c|c|c|}
\hline Time & Load condition & $\mathrm{PF}^{*}$ & $\begin{array}{l}\text { Compensation } \\
\text { model }\end{array}$ \\
\hline $0.0-0.25$ & $\begin{array}{l}P_{L=}=0 \mathrm{MW}, Q_{L=}=0 \mathrm{MVar} \\
P_{L \beta}=\mathrm{MMW}, Q_{L \beta}=6 \mathrm{Mvar}\end{array}$ & No RPFC & - \\
\hline $0.2-0.45$ & $\begin{array}{l}P_{L=}=0 \mathrm{MW}, Q_{L=}=0 \mathrm{Mvar} \\
P_{L \theta}=8 \mathrm{MW}, Q_{L \mathscr{\delta}}=6 \mathrm{Mvar}\end{array}$ & 1 & FCM \\
\hline $0.4-0.65$ & $\begin{array}{l}P_{L=}=8 \mathrm{MW}, Q_{L=}=6 \mathrm{Mvar} \\
P_{L \theta}=8 \mathrm{MW}, Q_{L \theta}=6 \mathrm{Mvar}\end{array}$ & & \\
\hline $0.6-0.85$ & $\begin{array}{l}P_{L=}=8 \mathrm{MW}, Q_{L z}=6 \mathrm{Mvar} \\
P_{L \sigma}=0 \mathrm{MW}, Q_{L \sigma}=0 \mathrm{Mvarr}\end{array}$ & & \\
\hline $0.8-1.05$ & $\begin{array}{l}P_{L=}=0 \mathrm{MW}, Q_{L=}=0 \mathrm{MVar} \\
P_{L \sigma}=8 \mathrm{MW}, Q_{L \sigma}=6 \mathrm{Mvar}\end{array}$ & 0.95 & Mode1-2 \\
\hline
\end{tabular}

\section{Case 1: PI CONTROLLER}

The waveforms represents the primary three phase currents, power factor, voltage and current unbalance ratio, capacity of RPFC when it is driving a constant load with variable power factor.It demonstrates the three phase load changes

such that the primary PF move along $\mathrm{PF}^{*}$ with the satisfactory execution. Also, $\mathrm{iA}, \mathrm{iB}$, and $\mathrm{iC}$ have a tendency to be the adjusted three phase currents when $\mathrm{PF}^{*}$ wound up bigger.The waveforms in the condition of variable $\mathrm{PF}^{*}$

with constant load. Fig 5.3 represents the Primary three phase currents.Fig 5.4 represents the PF* and PF. Fig 5.5 represents the Voltage's and current's unbalanced ratio. Fig 5.6 represents the Capacity of RPFC 

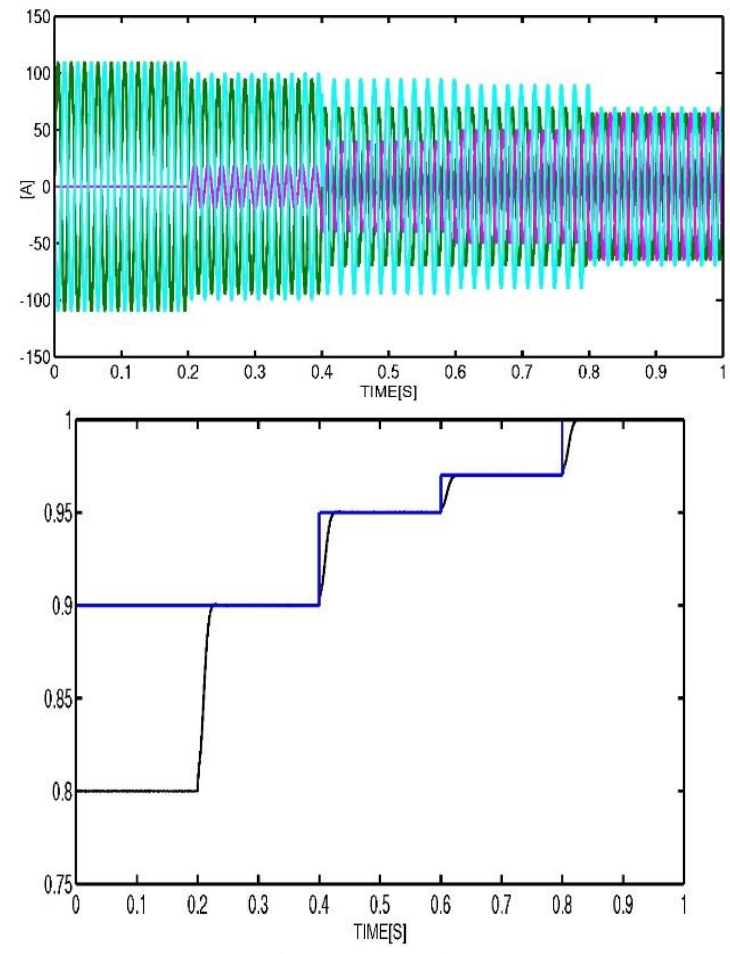

Fig 5.4: $\mathrm{PF}^{*}$ and $\mathrm{PF}$

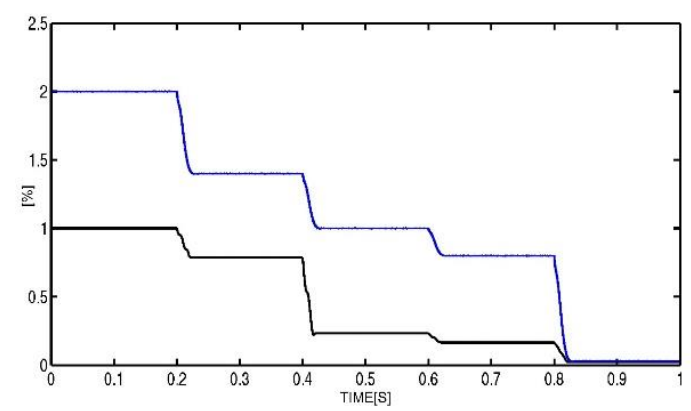

Fig 5.5: Voltage and Current Unbalance ratio

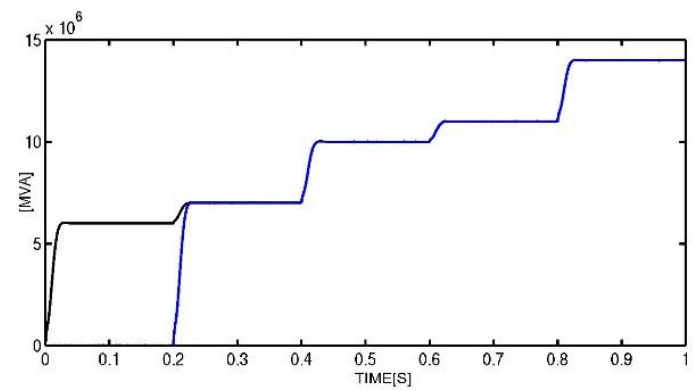

Fig 5.6: Capacity of RPFC

b) The waveforms represents the primary three phase currents, power factor, voltage and current unbalance ratio, capacity of RPFC when it is driving variable load with constant power factor.It demonstrates the three phase load changes such that the primary PF move along $\mathrm{PF}^{*}$ wth the satisfactory execution. Also, $\mathrm{iA}, \mathrm{iB}$, and iC have a tendency to be the adjusted three phase currents when $\mathrm{PF}^{*}$ wound up bigger.

The waveforms in the condition of variable $\mathrm{PF}^{*}$ with constant load. Fig 5.7 represents the Primary three phase
currents.Fig 5.8 represents the $\mathrm{PF}^{*}$ and PF. Fig 5.9 represents the Voltage's and current's unbalanced ratio. Fig 5.10 represents the Capacity of RPFC

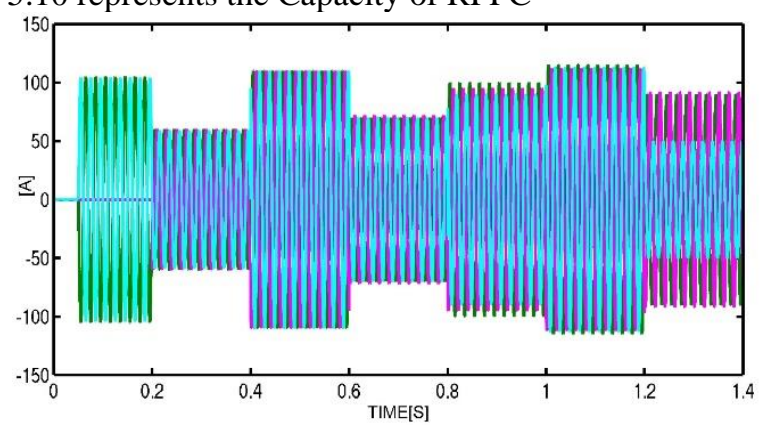

Fig 5.7: Primary three phase currents.

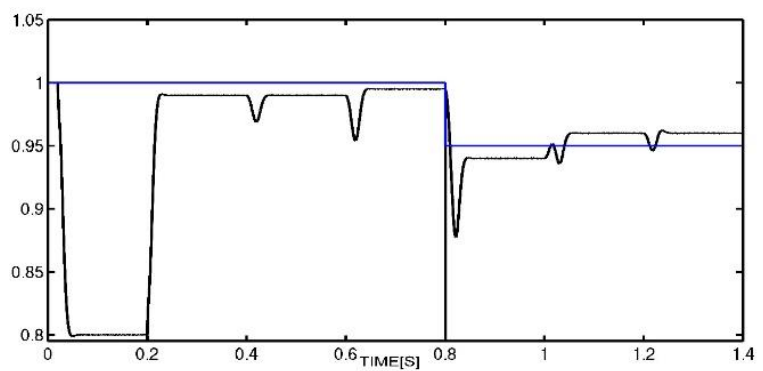

Fig 5.8: $\mathrm{PF}^{*}$ and $\mathrm{PF}$

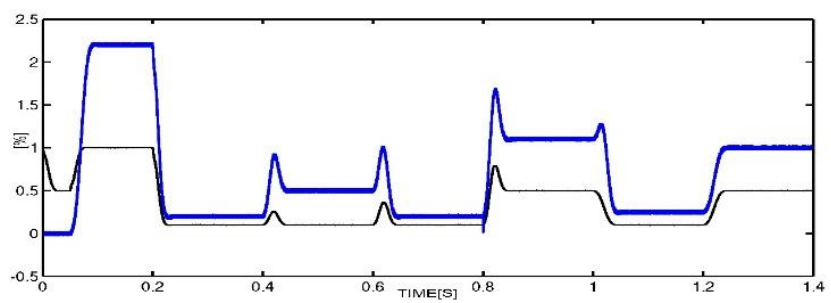

Fig 5.9: Voltage and Current Unbalance ratio

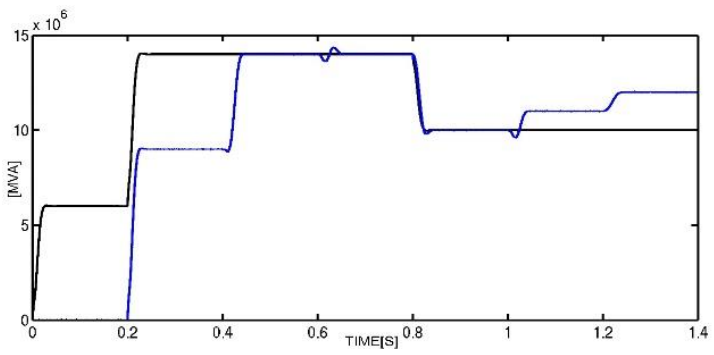

Fig 5.10: Capacity of RPFC

\section{Case 2 : FUZZY CONTROLLER}

a) The waveforms represents such that the primary three phase currents, power factor, voltage and current unbalance ratio, capacity of RPFC when it is driving a constant load with variable power factor of a FUZZY based controller .It demonstrates the three phase load changes such that the primary $\mathrm{PF}$ move along $\mathrm{PF}^{*}$ with the satisfactory execution. Also, iA, iB, and iC have a tendency to be the adjusted three phase currents when $\mathrm{PF}^{*}$ wound up bigger. 
The waveforms in the condition of variable $\mathrm{PF}^{*}$ with constant load. Fig 5.11 represents the Primary three phase currents.Fig 5.12 represents the $\mathrm{PF}^{*}$ and PF. Fig 5.13 represents the Voltage's and current's unbalanced ratio. Fig 5.14 represents the Capacity of RPFC

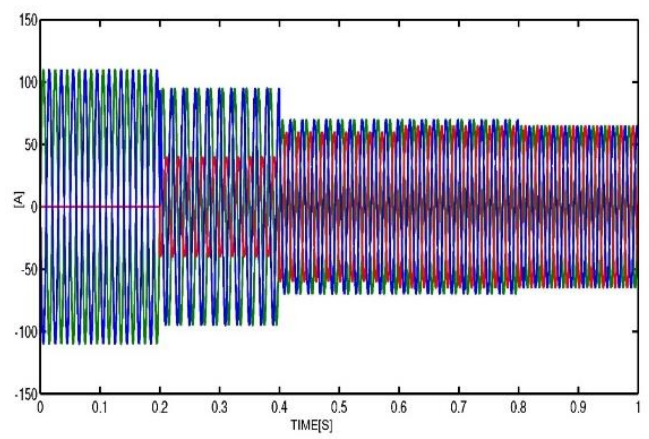

Fig 5.11 Primary Three Phase currents using fuzzy controller

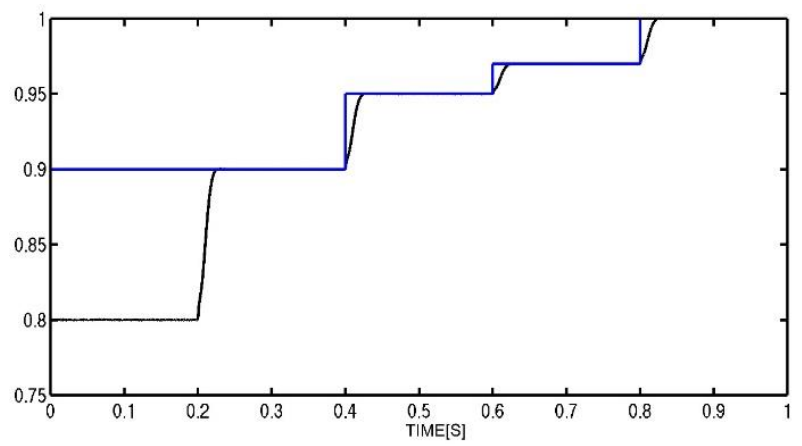

Fig 5.12 PF VS PF* using Fuzzy controller

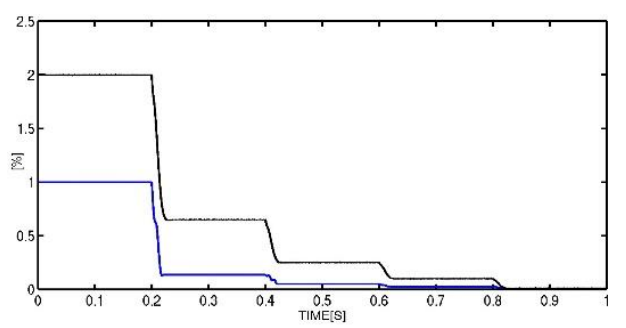

Fig 5.13 Voltage and Current unbalance ratio using Fuzzy controller

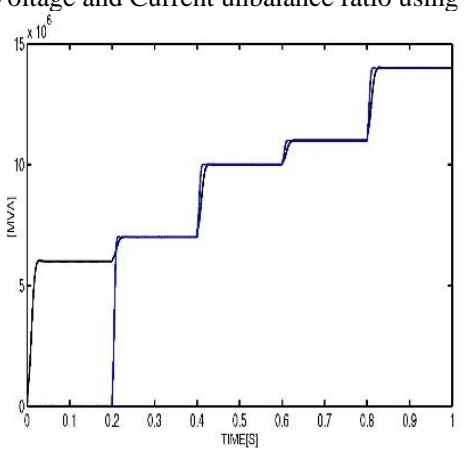

Fig 5.14 Capacity of RPFC using fuzzy controller

b) The waveforms represents such that the primary three phase currents, power factor, voltage and current unbalance ratio, capacity of RPFC when it is driving a variable load with constant power factor of a FUZZY based controller .It demonstrates the three phase load changes such that the primary PF move along $\mathrm{PF}^{*}$ wth the satisfactory execution. Also, iA, iB, and iC have a tendency to be the adjusted three phase currents when $\mathrm{PF}^{*}$ wound up bigger.

The waveforms in the condition of variable $\mathrm{PF}^{*}$ with constant load. Fig 5.15 represents the Primary three phase currents.Fig 5.16 represents the $\mathrm{PF}^{*}$ and PF. Fig 5.17 represents the Voltage's and current's unbalanced ratio. Fig 5.18 represents the Capacity of RPFC

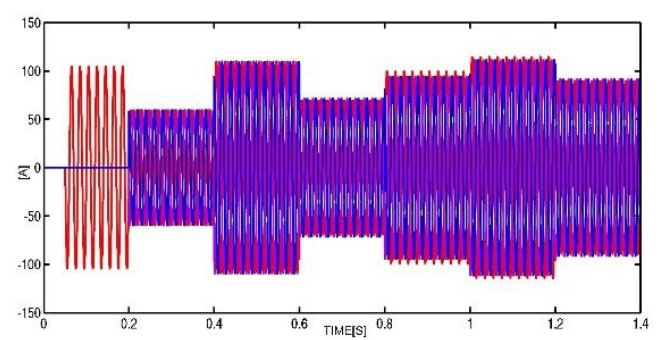

Fig 5.15 Primary three phase currents using fuzzy controller

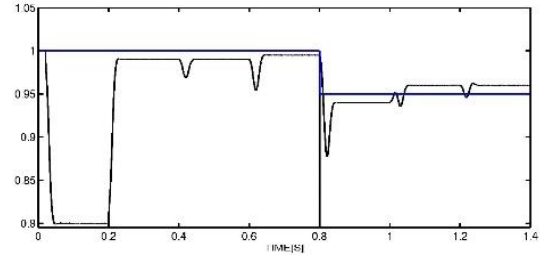

Fig 5.16 PF VS PF* using fuzzy controller

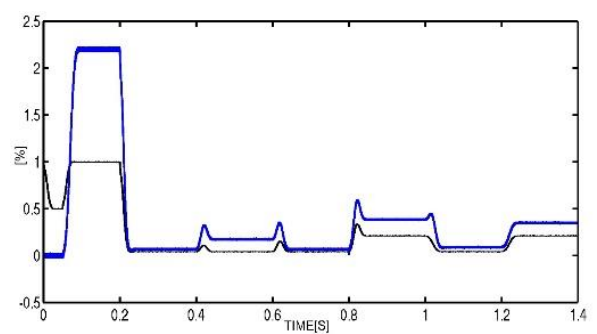

Fig 5.17 Voltage and current unbalance ratio using fuzzy controller

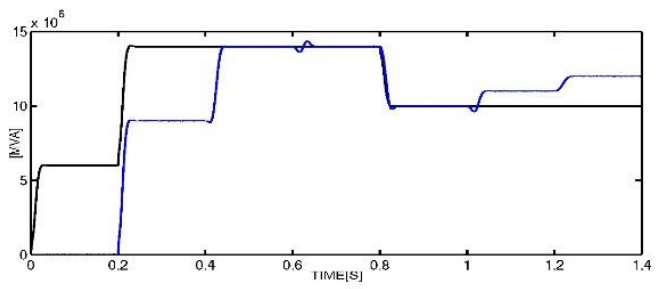

Fig 5.18 Capacity of RPFCusing fuzzy controller

\section{CONCLUSION}

This paper proposed a power factor arranged RPFC for the power quality improvement with both PI and FUZZY controller. The mathematical model of the RPFC coordinated ERPS and the far reaching plan technique for the proposed control methodology are given in detail, based on a genuine footing substation. The simulation and the exploratory results confirm the accuracy of the proposed considers. 
In the start of fulfilling the norms of the reactive power and NSV, this paper gives an ideal control technique for the PQ improvement, control adaptability upgrade, and the lessening of RPFC's remunerating and planning limit in two or single phase RPFC incorporated ERPS. In other words, this control technique can influence the system to have an attractive high cost-effectiveness in two or single phase footing load conditions.

\section{REFERENCES}

[1] Sijia Hu, Member, IEEE, Bin Xie, Yong Li, Senior Member, IEEE, Xiang Gao, Zhiwen Zhang, Longfu Luo, Member, IEEE, Olav Krause, Member, IEEE, Yijia Cao, Senior Member, IEEE

[2] S. Chen, R. Li, and H.4 Hsiang, "Traction system unbalance problem- analysis methodologies," IEEE Trans. Power Del., vol. 19 , no. 4 , pp. $1877-1883$, Oct. 2004

[3] J. Kilter, T. Sarnet, and T. Kangro, "Modelling of high-speed electrical railway system for transmission network voltage quality analysis: Rail Baltic case study," in Proc. Elect. Power Qual. Supply Reliab. Conf. (PQ), 2014, pp. 323-328.

[4] Z. He, H. Hu, Y. Zhang, and S. Gao, "Harmonic resonance assessment to traction power-supply system considering train model in China high-speed railway," IEEE Trans. Power Del., vol. 29, no. 4, pp. 1735-1743, Aug. 2014.

[5] G. Raimondo, P. Ladoux, A. Lowinsky, H. Caron, and P. Marino, "Reactive power compensation in railways based on AC boost choppers," IET Electr. Syst. Transp., vol. 2, no. 4, pp. 169-177, Jua. 2012

[6] Z. Zhang, Y. Li, L. Luo, P. Luo, Y. Cao, Y. Chen et al, "A new railway power flow control system coupled with asymmetric double LC branches," IEEE Trans. Power Electron., vol. 30, no. 10, pp. 5484-5498, Oct. 2015

[7] S. Gazafrudi, A. Langerudy, E. Fuchs, and K. Al-Haddad, "Power quality issues in railway electrification: a comprehensive perspective," IEEE IEEE Trans. Ind. Electron., vol. 62, no. 5, pp. 3081-3090, May. 2015

[8] T. Uzuka, "Faster than a speeding Bullet: An overview of Japanese high-speed rail technology and electrification," IEEE Electrification Mag., vol.1, no.1, pp. 11-20, Sep. 2013.

[9] M. Brenna, F. Foiadelli, and D. Zaninelli, "Electromagnetic model of high speed railway lines for power quality studies," IEEE Trans. Power Syst., vol. 25, no. 3, pp. 1301-1308, Aug. 2010.

[10] H. Wang, Y. Liu, K. Yan, Y. Fu, and C. Zhang, "Analysis of static VAr compensators installed in different positions in electric railways," IET Elect. Syst. Transp., vol. 5, no. 3, pp. 129-134, Jan. 2015.

[11] G. Zhu, J. Chen, and X. Liu, "Compensation for the negativesequence currents of electric railway based on SVC," in Proc. ICIEA. Conf., 2008, pp. 1958-1963.

[12] K. Fujii, K. Kunomura, K. Yoshida, A. Suzuki, S. Konishi, M. Daiguji et al., "STATCOM applying flat-packaged IGBTs connected in series," IEEE Trans. Power Electron., vol. 20, no. 5, pp. 1125-1132, Sep. 2005

[13] R. Grunbaum, J. Hasler, T. Larsson, and M. Meslay, "STATCOM to enhance power quality and security of rail traction supply," in Proc. 8th Int. Symp. Adv. Electro-Mech. Motion Syst. Electr. Drives, Lille, France, 2009, pp. 1-6.

[14] A. Bueno, J. Aller; J. Restrepo, R. Harley, T. Habetler, "Harmonic and unbalance compensation based on direct power control for electric railway systems," IEEE Trans. Power Electron., vol.28, no.12, pp. 5823-5831, Dec. 2013.

[15] B. Gultekin, C. Gercek, T. Atalik, M. Deniz, N. Bicer, M. Ermis et al., "Design and implementation of a 154-kV \pm 50 -Mvar transmission STATCOM based on 21-level cascaded multilevel converter," IEEE Trans. Ind. Appl., vol. 48, no. 3, pp. 1030-1045, May. 2012.

[16] P. Ladoux, G. Raimondo, H. Caron, and P. Marino, "Choppercontrolled steinmetz circuit for voltage balancing in railway substations," IEEE Trans. Power Electron., vol. 28, no. 12, pp. 5813-5882, Dec. 2013.
[17] S. Senini and P. Wolfs, "Hybrid active filter for harmonically unbalanced three phase three wire railway traction loads," IEEE Trans. Power Electron, vol. 15, no. 4, pp. 702-710, Jul. 2000

[18] S. Rahmani, A. Hamadi, K. Al-Haddad, and A. Dessaint, "A combination of shunt hybrid power filter and thyristor controlled reactor for power quality," IEEE Trans. Ind. Electron., vol. 61 no. 5, pp. 2152-2164, May. 2014.

[19] H. Akagi and K. Isozaki, "A hybrid active filter for a three-phase 12-pulse diode rectifier used as the front end of a medium-voltage motor drive," IEEE Trans. Power Electron., vol. 27, no. 1, pp. 69-77, Jan. 2012.

[20] A. Bhattacharya, C. Chakraborty, and S. Bhattacharya, "Parallel connected shunt hybrid active power filters operating at different switching frequencies for improved performance," IEEE Trans. Ind. Electron., vol. 59, no. 11, pp. 4007-4019, Nov. 2012.

[21] P. Tan, P. Loh, and D. Holmes, "Optimal impedance termination of $25-\mathrm{kV}$ electrified railway systems for improved power quality," IEEE Trans. Power Del., vol. 20, no. 2, pp. 1703-1710, Apr. 2005

[22] P. Tan, P. Loh, and D. Holmes, "A robust multilevel hybrid compensation system for 25-kV electrified railway applications," IEEE Trans. Power Electron., vol. 19, no. 4, pp. 1043-1052, Jul 2004.

[23] S. Hu, Z. Zhang, Y. Li, L. Luo, Y. Cao, and C. Rehtanz, "A new half-bridge winding compensation based power conditioning system for electric railway with LQRI," IEEE Trans. Power Electron., vol. 29, no. 10, pp. 5242-5256, Oct. 2014.

[24] S. Hu, Z. Zhang, Y. Chen, G. Zhou, Y. Li, L. Luo et al., "A new integrated hybrid power quality control system for electrical railway," IEEE Trans. Ind. Electron., vol. 62, no. 10, pp. 6222 6232, Oct. 2015.

[25] S. Hu, Y. Li, B. Xie, M. Chen, Z. Zhang, L. Luo et al., "A y-d multifunction balance transformer-based power quality contro system for single-phase power supply system," IEEE Trans. Ind. Appl., vol. 52, no. 2, pp. 1270-1279, Mar. 2016.

[26] T. Uzuka, S. Ikedo, K. Ueda, Y. Mochinaga, S. Funahashi, and K. Ide, "Voltage fluctuation compensator for shinkansen," Trans IEE Japan, vol. 162, no. 4, pp. 25-34, May. 2008.

[27] M. Ohmi, and Y. Yoshii, "Validation of railway static power conditioner in Tohoku Shinkansen on actual operation," in Proc. Int. Conf. Power Electron., 2010, pp. 2160-2164.

[28] A. Luo, F. Ma, C. Wu, S. Ding, Z, Shuai, and Q. Zhong, "A dualloop control strategy of railway static power regulator under $\mathrm{V} / \mathrm{V}$ electric traction system," IEEE Trans. Power Electron., vol. 26, no. 7, pp. 2079-2091, Jul. 2011.

[29] N. Dai, M. Wong, K. Lao, and C. Wong, "Modelling and control of a railway power conditioner in co-phase traction power system under partial compensation," IET Power Electron., vol. 7, no. 5, pp. 1044-1054, May. 2014.

[30] F. Ma, Q. Xu, Z. He, C. Tu, Z. Shuai, A. Luo et al., "A railway traction power conditioner using modular multilevel converter and its control strategy for high-speed railway system," IEEE Trans. Transp. Electrif., vol. 2, no. 1, pp. 96-109, Mar. 2016.

[31] D. Zhang, Z. Zhang, W. Wang, and Y. Yang, "Negative sequence current optimizing control based on railway static power conditioner in V/v traction power supply system," IEEE Trans. Power Electron., vol. 31, no. 1, pp. 2079-2091, Jan. 2016.

[32] B. Bahrani, and A. Rufer, "Optimization-based voltage support in traction networks using active line-side converters," IEEE Trans. Power Electron., vol. 28, no. 2, pp. 673-685, Feb. 2013.

[33] C. Zhao, D. Dujic, A. Mester, J. Steinke, M. Weiss, S. Schmid et al., "Power electronic traction transformer-medium voltage prototype," IEEE Trans. Ind. Electron., vol. 61, no. 7, pp. $3257-$ 3269, Jul. 2014

[34] D. Dujic, C. Zhao, A. Mester, J. Steinke, M. Weiss, S. Schmid et al., "Power electronic traction transformer-low voltage prototype," IEEE Trans. Power Electron., vol. 28, no. 12, pp 5522-5534, Dec. 2013

[35] Quality of Electric Energy Supply Admissible Three Phase Voltage Unbalance, National Standard GB/T 15543-2008, 2008.

[36] T. Kneschke, "Control of utility system unbalance caused by single-phase electric traction," IEEE Trans. Ind. Appl., vol. IA21, no. 6, pp. 1559-1570, Nov. 1985.

[37] F. Ciccarelli, M. Fantauzzi, D. Lauria, and R. Rizzo, "Special transformers arrangement for ac railway systems," in Proc. 
Electrical Systems for Aircraft, Railway and Ship Propulsion (ESARS), 2012, pp. 1-6.

[38] H. Akagi, E. Watanabe, and M. Aredes, Instantaneous power theory and applications to power conditioning. New Jersey, USA: IEEE Press, 2007.
[39] M. Miranbeigi, H. Iman-Eini, and M. Asoodar, "A new switching strategy for transformer-less back-to-back cascaded H-bridge multilevel converter," IET Power Electron., vol. 7, no. 7, pp. 1868-1877, Jan. 2014. 